\title{
CrimRxiv
}

\section{Treating Criminal Justice- Involved Clients with SMI in the Community}

Brittany Hood ${ }^{1}$

${ }^{1}$ Texas A\&M International University

Published on: Jan 31, 2022

DOI: $10.21428 / c b 6 a b 371.399088 \mathrm{eb}$

License: Creative Commons Attribution 4.0 International License (CC-BY 4.0). 


\section{ABSTRACT}

With criminal justice-involved individuals with serious mental illness (SMI) in the criminal justice system at an all-time high, research on community mental health centers (CMHCs) demonstrates a lack of treatment for justice-involved persons. Scholars have argued that providing appropriate treatment to criminal justice-involved individuals with SMI could ameliorate symptoms, and therefore, improve the effectiveness of mental health treatment to reduce recidivism in individuals who are criminal justice-involved with SMI diagnoses. Using a qualitative approach, the current study examined how community service providers explored the organizational-level variables and their effect on treatment decisions for justice-involved individuals with SMI. Findings suggest three important implications for policy and practice. First, CMHCs are remain underfunded. Second, service providers perceived their greatest law and budget constraints to be Medicaid driven. Third, and most importantly, collaboration with the criminal justice system can prevent clients from receiving the most appropriate treatment to address their criminogenic and mental health needs.

\section{Introduction}

Over two million individuals are currently incarcerated in the United States (Glaze \& Kaeble, 2013) and estimates suggest that incarcerated populations are disproportionately diagnosed with serious mental illness (SMI) (Prins et al., 2009). Despite the prevalence of SMI among the justice-involved, for almost half of a century collective evidence has revealed that treatment for incarcerated individuals with SMI has been lacking (Abramson, 1972; Barr, 2003) and fragmented (Mallik-Kane \& Visher, 2008). Further, although incarcerated settings have been labeled as modern day mental health hospitals, these settings do not prepare individuals to seek treatment upon release (Baillargeon et al., 2010; Barr, 2003). Despite this, criminal justiceinvolved individuals will most likely be required to participate in parole or probation upon their release and community-based mental health treatment.

Although this population is more likely to receive treatment in the community, as opposed to during incarceration, their re-arrest (Daniel, 2007) and re-incarceration rates (Bales et al., 2017) remain disproportionately high compared to their counterparts. Therefore, it is of the utmost importance to understand the nature of mental health treatment where individuals are most likely to receive treatment - in the community. More specifically, it is important to understand what organizational factors 
affect service provider's treatment decisions for this population. Better understanding of how service providers perceive their organizations to influence treatment decisions can suggest areas of improvement. Therefore, the current research provides insight into how community mental health center (CMHC) service providers perceive their organization's budget, goals, policies, as well as law, to affect treatment decisions.

\section{Literature Review}

Research has attempted to explain employee-level decision making in organizations. Yet, contemporary studies on decision making have largely ignored the role of organizational-level variables in mental health treatment. This section provides an overview of decision making literature from a variety of disciplines and suggests several organizational factors that are of importance in decision making processes and provide a basic framework to inform the current study. These factors can be organized into four domains including organizational budget, goals, policies, and law. It is important to note that although these domains are different, they are not mutually exclusive in that they can influence one another (Trompenaars, 1994).

\section{Organizational Budget}

Since the United States Congress enacted the Community Mental Health Act to provide federal funding for community-based and outpatient treatment centers (Fisher et al., 2009), it is difficult to disentangle CMHC budgets from law. CMHCs are largely nonprofit organizations funded primarily by the legislature, but they also rely heavily on low reimbursement rates from Medicaid (Cunningham \& O’Malley, 2008). Although budgets are typically considered outside of the scope of job-related responsibilities for employees like service providers, from a decision-making perspective it is well known that budget influences what choices are available (Keogh et al., 2020; Pierse et al., 2021). In part, organizations rely heavily on evidence-based practices to address some aspects of budget (as well as policy) (Bowen \& Zwi, 2005).

While research on healthcare decision-making has continued to proliferate since the early 2000s (Guindo et al., 2012), research that explores budget remains limited (Keogh et al., 2020). According to early research, Siegler (1985) explained how budget and quality of care act in a trade-off relationship; in the age of bureaucracy, budget and cost efficiency are assessed using a bureaucratic risk-benefit analysis. In other words, organizations will prioritize cost over the appropriateness of treatment. More recent research suggests that budget can restrict what treatment options are available (Keogh et al., 2020). In this study, the authors examined how resource allocation 
affected dementia treatment decisions in Irish home and community care settings. Their findings suggest that when providers are free of budgetary constraints, there are a broader range of services available for clients. Logic would suggest that the role of budget might function similarly to mental health treatment decisions in the United States.

\section{Organizational Goals}

In the 1970s, the mental health client movement shifted healthcare decision making from the provider to a collaborative process between the provider, client, and sometimes the family, with the intent of emphasizing the client's wants (Adams \& Grieder, 2013). Consequently, several changes have occurred in how physical and mental health decisions are made in the United States. Two of the greatest changes in these fields are the idea of shared decision making and client-centered care. Shared decision making emphasizes the importance of the decision making process and the outcomes of treatment, which ultimately improves long-term outcomes as clients are more likely to actively participate in their treatment if they were part of the decision (Légaré \& Witteman, 2013). Patient- or client-centered care is similar to, but distinct from, the shared decision making model. Like shared decision making, patientcentered care centers on client's self-determination or the right to make decisions related to their own healthcare. This type of treatment considers the client's backgrounds and family history to understand the needs and goals of an individual to improve outcomes and quality of care (Castro et al., 2016).

\section{Organizational Policy}

Policy can be written or unwritten and, therefore, can come from policy and procedure handbooks, influenced by state and federal law, or can originate from the inherent nature of the organization and those working within it. Early research on policy and decision-making assumed that individuals within organizations shared a purpose and the means to which they achieved this purpose. Put another way, decision makers within organizations were assumed to function closely or were tightly coupled. Contrary to common scholarly suppositions at the time, Weick (1976) proposed that organizations are complex and comprised of loosely coupled elements. Weick's assumption posited that individuals who work together, within and between organizations, are often not synergistic in their goals and the means to reach those goals. From Weick's perspective, decision making disparities can be understood by the strength of organizational coupling. 
Later research explored the role of discretion when employees work under vague policies without proper resources. Decision-makers must employ discretion to deliver services and resources (Lipsky, 1980). Although Lipsky (1980) asserts that decision makers should exercise considerable amounts of discretion, the rules which shape their agencies can simultaneously impede decision-makers. He described the inadequate resources and difficult working conditions of criminal justice actors, which can be summed up in a few words-the dilemma of supply and demand. A situation that is not novel to either the criminal justice or CMHC systems, particularly as it relates to high caseloads (Gayman et al., 2018) primarily comprised of complex client needs (Korasz et al., 2018). Empirical evidence also suggests that an organization's size and employee's autonomy can influence decision making. Research shows that organization size and employee autonomy are related in that they effect the extent to which decision-makers work collectively or in silos (Arazan et al., 2019; Ulmer \& Bradley, 2006).

Nowadays, evidence-based practices provide some guidance for decision makers. Organizational policies and practices continue to be informed by evidence-based practice, and are particularly important in the field of healthcare (Aarons et al., 2009). In 2014, Obama's Affordable Care Act of 2014 mandated the implementation of evidence-based treatments in healthcare organizations (Beidas et al., 2013). Thus, it is unsurprising that evidence-based practices influence treatment decisions (Janati et al., 2018).

\section{Law}

One cannot discuss the effects of law on treatment decisions without acknowledging how healthcare law has affected mental health treatment (Morata, 2018).

Deinstitutionalization, probably the most notable of the law's effects on treatment, was the process of replacing long-stay psychiatric hospitals with federally funded CMHCs (Brown \& Lewis, 2015) and private mental health providers (Kennedy-Hendricks et al., 2016). The goal of deinstitutionalization was to transition institutionalized individuals with mental illness into the community where they could receive community-based mental health services (Frank \& Glied, 2006). However, previously institutionalized individuals with SMI faced difficulty in management of their biological, psychological, and social needs and consequently became homeless, resulting in increased exposure to law enforcement officers (Lamb \& Weinberger, 1998), incarceration and reincarceration (Daniel, 2007). 
More recent laws have also affected treatment decisions for this population. For example, as previously mentioned, Obama's Affordable Care Act of 2014. Also consider the Medicaid and Medicare Patient Self Determination Act of 1990 required healthcare organizations to inform clients of their right to make their own treatment decisions. Medicaid is the largest payer source for mental health treatment in the United States (Cummings et al., 2013). However, Medicaid is often one of the first budgets the government cuts (Berk \& Schur, 1998). Other research has found that clients with private insurance had a higher likelihood of receiving both psychological treatment and medication, compared to clients with Medicare, Medicaid, and other payer sources (Goldberg \& Lin, 2017). Additionally, while Medicaid is known to improve access to health services the level of care covered under Medicaid is less than what is covered under private insurances (Berk \& Schur, 1998) and approximately one-third of CMHC organizations do not accept Medicaid insured clients (Cummings et al., 2013; Goldberg \& Lin, 2017).

More broadly, Jecker et al. (2011) and Whiteford (2019) explored what barriers exist due to the ambiguity of healthcare law; laws can lack specificity in how organizations should implement or change policies to align with legislation. Vague language can cause conflicting policies across organizations due to individual interpretations (Jecker et al., 2011) and leads to uncertainty in healthcare clinicians (Stewart, 2011). Additionally, one of the largest obstacles for mental health treatment is legislative funding (Elpers, 1989). In California, scholars studied the actual expenditures for funding CMHCs and found that between 1973 and 2006 the budget for mental health had decreased almost every year and overall had declined by $11.8 \%$. Insufficient legislative funding is not new nor is it limited to California's mental health system (Yank et al., 1992). Still, in the $21^{\text {st }}$ century, despite mass incarceration and the number of individuals who experience reentry, CMHCs suffer from inadequate funding (Bonfine et al., 2019; Lurigio, 2011).

\section{Method}

To ascertain how CMHC service providers perceive organizational-level variables to affect treatment decisions for individuals with criminal justice involvement and SMI, this study draws on data from 61 in-depth, semi-structured interviews conducted between December 2019 and April 2020 with service providers in Indiana. Questions from the interview guide were largely open-ended and asked service providers to reflect on how budget, goals, policy, and law affected their treatment for criminal 
justice clients with SMI. The researcher posed and probed questions for service providers to elaborate on their answers. Interviews lasted one hour on average.

\section{Recruitment}

In Indiana, the CMHC system is comprised of 24 independent county-based organizations. Recruitment began once an administrator at each organization was identified. Administrators at a total of 45 CMHCs were identified; a number of CMHCs service multiple counties. Out of the 45 total organizations, three (6.7\%) CMHCs declined participation. Eighteen organizations either did not respond or failed to provide service provider contact information. Of the remaining organizations, 16 (35.6\%) administrators agreed to participate in the current study. Next, a second email requested names and contact information for eligible service providers. Service providers were considered eligible if they provided services to an active caseload and at least one of their clients were criminal justice-involved with a SMI diagnosis. Using a combination of purposive (74\%) and snowball sampling methods (26\%), all eligible service providers received a recruitment email. Those who were interested responded to the researcher via email or phone. Interviews were scheduled with approval from the organization's administrator to be conducted during the workday at the service provider's convenience. Interviews were conducted by the principal investigator via Zoom and were audio recorded with permission of the service provider, and transcribed verbatim.

\section{CMHC and Service Provider Background}

The CMHCs that agreed to participate were in primarily urban areas (74\%) with a population of at least 50,000 and represent over 31.5\% of Indiana counties. While each organization was located in a particular county, some service providers delivered direct care in multiple counties. Nine service providers self-reported that they provide direct care in more than one county. This is important because funding and jail policies vary by county, which can impact the type of services available for criminal justice clients with SMI.

Table 1: Service Provider Demographics
Variable
Total Sample $(N=61)$
$N(\%)$
Female
$45(74.0 \%)$ 


\begin{tabular}{|l|l|}
\hline White & $58(95.0 \%)$ \\
\hline Non-Hispanic & $58(95.0 \%)$ \\
\hline $\begin{array}{l}\text { Education } \\
\text { Bachelor's Degree } \\
\text { Master's Degree }\end{array}$ & $2(3.3 \%)$ \\
\hline $\begin{array}{l}\text { Licensed Clinical Social Worker } \\
\text { Licensed Clinical Mental Health Counselor }\end{array}$ & $49(11.5 \%)$ \\
\hline $\begin{array}{l}\text { Doctorate } \\
\text { Asso.3\%) }\end{array}$ & $5(8.0 \%)$ \\
\hline
\end{tabular}

As shown in Table 1, the sample was comprised of predominately non-Hispanic, white females with master's degrees. Although respondents were not probed for their area of discipline, several respondents spontaneously offered their licensure information. The most common degrees mentioned were Licensed Clinical Social Worker (LCSW) and Licensed Mental Health Counselor (LMHC), 16\% $(n=10)$ and 8\% $(n=5)$ respectively.

\section{Analytic Strategy}

Using a team-based iterative-inductive approach (Cascio et al., 2019), the researcher and one undergraduate research assistant qualitatively analyzed interviews in four stages using NVivo 12. First, each coder individually listened to three interviews to create a preliminary codebook of themes derived from the data. In the second stage, the coders compared individual codebooks and agreed on a combined preliminary codebook. Next, each coder individually coded the same transcript using the preliminary codebook. Coders then met to compare codes and discuss possible changes to the codebook. In the fourth stage, the coding team individually coded the remaining 58 transcripts. Throughout all analytic stages, memos and analytic notes were written to document results and decision making processes (Saldana, 2015). Inter-coder reliability in team-based coding is paramount to qualitative analysis. Using NVivo's comparison query, inter-rater reliability was assessed as high, with kappa values exceeding 0.87. Discrepancies were discussed by both coders and a consensus was reached prior to continuing with stage four of coding.

The coders employed attribute coding of service provider demographic information and magnitude coding to capture the prevalence of individuals with criminal justice 
involvement and SMI on a service provider's caseload (Saldana, 2015). More simply, attribute coding can be thought of as qualitative coding for categorical data. Second, magnitude coding is used when a coded datum is numeric in nature such as a frequency or percentage. All other data from the interviews were coded using the eclectic coding method which places codes under themes (Saldana, 2015).

\section{Findings}

The qualitative analysis yielded six themes related to budget, goals, policy, and law: CMHCs are underfunded, the generalizability of CMHC goals, appropriateness of treatment, influences on CMHC policies, law as the greatest barrier, and the role of Medicaid. It is worth noting, as indicated by the literature review, that many barriers are interconnected and not mutually exclusive.

\section{CMHCs are Underfunded}

Most respondents (79\%) reported budgetary barriers in treating this population. The influence of budget was best described by an administrative supervisor with over 50 years of experience. He said, “[b]ack then you know, we really didn't know a lot and there was tons and tons and tons of money to do research and to understand things better...now that we have some really good ideas about what works, we don't have the money to implement it. Which is very frustrating for us." In total, respondents identified three primary ways their organization's budget affected their decision making: staffing, service provider training, and lack of treatment resources.

\section{Resources Organizational Staffing}

CMHCs must maintain staffing to provide appropriate mental health treatment for their clients. However, a sizeable percentage (54\%) of service providers reported that their organization's budget made maintaining necessary levels of staff difficult as they were unable to provide attractive and competitive salaries for qualified service providers. Barriers in the way of offering a competing salary mean organizations are “constantly understaffed because we can't pay people like other organizations do" and staffing directly relates to what and how much treatment can be provided. Another administrative service provider described how addressing budget and staffing concerns may exasperate the current problems as the need for treatment is too great. He said, "that would open the flood gates from...the criminal justice system." He predicted current caseload sizes of 35 would increase to 100 clients, which would mean their organization would need more recovery coaches and therefore, additional 
financial resources. He wasn't the only service provider to express this concern as others explained that there simply is not enough manpower compared to the treatment need in the community. One respondent candidly explained, "I could sit in this clinic twenty-four hours a day, seven days a week and there would still be more people who need me." It's worth noting that these findings were particularly salient in rural CMHCs. Almost one-fifth $(\mathrm{n}=12)$ of the sample proffered how budgetary restrictions related to staffing and commensurate salaries were exacerbated in rural Indiana counties. This sentiment was echoed by many service providers and was most clearly described by a supervisor, who stated that "I will tell you this and tell you this very candidly. We are...in rural Indiana...master's level therapists, certified therapists are as rare as hen's teeth around here."

\section{Service Provider Training}

Related to staffing and commensurate salaries, Indiana CMHCs experience high turnover rates particularly in rural southern counties, near Ohio and Kentucky. An administrative service provider described how newly graduated or less experienced staff receive their on-the-job training only to leave their rural CMHC or the state of Indiana for a higher paying job:

We sometimes lose, not sometimes, we do lose great clinicians to better paying jobs...we have a lot of interns, who are close to receiving their master's. It's not unusual for them to either leave as soon as their internship is completed or stay long enough to get their full licensure...because they can take that same degree now... go get a job somewhere else that pays more.

On one hand, service providers described the financial responsibility of CMHCs to provide expensive training for new hires. On the other hand, approximately one-fourth (14.7\%) of respondents described their organization's training budget as limited or completely lacking. For example, one addictions therapist reported that since being hired they had received no training. Moreover, when respondents were asked if they needed any additional training or supervision to provide appropriate treatment to this population over $60 \%(n=37)$ of service providers answered in favor of more training. While the most common training needs were related to newer treatment modalities, other service providers expressed how unfamiliarity with the criminal justice system was a barrier to treating this population of individuals, and therefore, criminal justicespecific training would be beneficial.

\section{Lack of Treatment Resources}


Of the service providers who reported budgetary barriers, a sizeable percentage (34\%) referred to treatment provisions. Not surprisingly, most service providers perceived a lack of financial resources for new and innovative treatment or to expand current treatment (e.g., workbooks and paid videos that are companion pieces to curriculum). Other treatment needs included the implementation of technology, financial resources to pay for client medications, a local mental health court, transitional and residential programs, intensive outpatient treatment, step-down programs, transportation resources, modified intensive outpatient treatment, assertive community treatment (ACT) teams, gender-specific group programming, and a mobile unit to follow up on transitional populations from custody and incarceration into the community.

\section{Generalizability of CMHC Goals}

Respondents largely ( $\mathrm{n}=34,55 \%)$ described their organization's goals as generalizable for all clients rather than specific goals for criminal justice-involved clients with SMI. Organizational goals were largely described as client-centered and focused on the whole person. For example, one service provider explained, "whatever is best for the patient, that's what's going to drive treatment." Relatedly, an addictions social worker explained how generalizable goals allow for treatment flexibility in working with criminal justice clients, who are most likely mandated to CMHC treatment. An addictions therapist and jail coordinator described the rationale behind not treating client's criminogenic behavior specifically, "So, I think [organization] as a whole is all about trying to treat the disease, not the crime because the crime is part of the disease."

While most service providers felt positively about the general treatment goals, others expressed concern with the lack of specificity and attention to criminal justice involvement. An administrative service provider with decades of experience articulated his concerns as, "I don't think they really have a well-organized system for dealing with it really. I don't really think they see the bigger picture of the recidivism." He went on to explain that the generalizability may be explained by budgetary concerns, "We have a lot of priority for trying to survive you know as the mental health centers become more and more concerned as they go forward with financial issues, so just making a living."

Although most respondents reported generalizable goals, one-third $(n=18,30 \%)$ reported more specific goals for this population. Those service providers similarly described treatment goals as client-centered. However, the primary difference between this dichotomy of service providers was whether client-centered treatment 
was in light of criminal offending to "avoid recidivism... [or simply] to help people live healthy and productive lives." Following this distinguishing purpose, commonalities in responses stopped. Further analysis of these data indicated that their organization's goals were broad, multi-faceted, and varied by organizations. For example, one therapist reported her organization's goal as promoting community integration, so clients are in "the community and living without so much structure." Others delineated goals that addressed specific barriers for this population faces in the community including expending resources for clients to obtain housing, acquire health insurance, and apply for other state benefits such as food stamps and disability. In these cases, service providers emphasized the benefit of individualized treatment as not all clients face the same barriers.

In some cases, service providers stated that their organization's specific goals originated out of grant funded forensic projects or programs aimed at the rehabilitation of criminal justice clients with SMI. Interestingly, just under half $(\mathrm{n}=8$, $44.4 \%$ ) of these service providers discussed goals geared towards addressing recidivism in clients with co-occurring SMI and substance use diagnoses (SUDs). For example, one organization implemented a SUD committee dedicated to providing higher level care for SUD clients who "the majority of them come from the criminal justice system." Moreover, given the complexity of the needs of clients with cooccurring SUD and SMI diagnoses, this subgroup of service providers described their goal to treating this population by stating, "[y]ou know we're willing to give them just everything that we can, and we addressed their criminal thinking along with the addiction" and through a focus on client-centered care to "maximize therapeutic functionality across all domain functionality." Unfortunately, the latter service provider expanded upon their goal to state that while their goal is to address all domains, "in the trenches it doesn't always execute."

\section{Influences on CMHC Policy}

Like goal-related findings, most service providers (68\%) reported general policies for all clients. Of the $32 \%$ of service providers who reported policies specific to criminal justice clients, most referred to unwritten policies and practices such as the commonplace practice of assigning criminal justice-involved clients to moral recognition therapy (MRT) groups designed to address substance abuse and criminogenic behaviors, other group programming, and evaluation for medication. Regardless of the specificity of organizational policies, most service providers (72\%) identified at least one policy-related barrier related to providing treatment to this 
population. The most common policy-related barriers fell into one of three types: criminal justice policies, insurance-related, and client-related.

First, 20 respondents described how their treatment decisions were restricted by criminal justice policies such as mandatory reporting of positive drug screens, zero tolerance policies, and the disjointed nature of the community mental health and criminal justice systems. Most concerning was how the criminal justice system's expectations can impact client-provider rapport. For example, some service providers discussed how the criminal justice system (e.g., probation) expects complete therapeutic reports for all clients. However, they argued that criminal justice partners only need to know that their mutual client is participating in treatment rather than a complete report of their life history, trauma, and other privileged discussions with their provider(s). Other service providers discussed how mandated drug screen reporting and the criminal justice system's zero tolerance policies run counter to a therapeutic environment. A licensed social worker aptly described how immediate abstinence from any substance "is unrealistic" when seeking sobriety. Instead, respondents proffered how relapses can provide a teaching opportunity for clients and how zero tolerance policies are fear based in that "it'll get you in the door, but it won't get you through treatment." In the end, service providers reported that when criminal justice policies require detailed reporting, clients viewed their provider as an extension of the criminal justice system, and only hindered their ability to treat this population.

Second, in many cases CMHC policies are influenced by the primary insurer of this population of clients, Medicaid. Service providers who reported Medicaid-driven policy barriers described how such requirements influenced their CMHC's policies related to reporting and documentation, and consequently significantly reduced the amount of time available for treatment. Service providers painfully described the process of insurance documentation, including when documentation must take place - during the allotted treatment period. Further complicating timing were criminal justice documentation requirements. Consider one service provider's breakdown of a 60minute appointment and how much time is dedicated to paperwork rather than treatment. He said, "time is of the essence and so we have 52 minutes basically. Fifty minutes to work with clients, right around there, and then we have ten minutes to do paperwork and sometimes when people are involved with the criminal justice system we have more than ten minutes of paperwork...they recommend concurrent documentation...it's kind of difficult sometimes." 
Respondents also expressed frustration with Medicaid's automatic cancelation policy when individuals are incarcerated even for a short period of time. For clients who are initially uninsured, they must seek Medicaid funding which can take up to six months to become effective. After being insured, even if clients are active in their treatment, once incarcerated for any length of time their Medicaid benefits are cancelled. However, the client must still participate in mandated treatment upon release. To do so, clients must reapply for Medicaid coverage which starts the approval process over and perpetuates an interruption in the continuity of care for this population.

Surprisingly, seven service providers explained that they circumvented this barrier by providing treatment outside of non-billable hours for the benefit of their client.

Another commonly reported Medicaid-driven barrier restricts who can provide services. According to service providers, Medicaid only reimburses for services provided by licensed clinical social workers (LCSW) or health service provider in psychology (HSPP). Respondents described how this policy is counter-intuitive given that the most common degree, licensed mental health counselor's (LMHCs), are restricted from providing services through Medicaid. Further, an administrative service provider with 25 years of experience also explained that "the sad part about it is a LMHC is really trained more thoroughly in mental health because that is what the MHC is for, mental health. Where the social worker is far more broad (sic) in what we do." This policy restriction is particularly problematic given budget-driven staffing challenges.

Relatedly, which services are covered by Medicaid (and any insurance) was also a major concern. Service providers explained how some therapeutic experiences are impossible to bill for even if they have value. For example, one case manager described how this makes treatment difficult, "[t]he spirit of what we're trying to do for these people, and this is the area where the paperwork does not get like the gestalt of it." She went on to provide some examples, "honestly if I can't document on paper that I've taught them 18 different coping mechanism for depression, but they're not connected to any prosocial activity that gives them a reason to apply those tools to engage in their life, I have not really improved their live at all" or "I can't bill for like, took the client for a walk in the park on a sunny day to get them some vitamin D and make them realize they enjoy being outside. So, they have a reason to get up and wash their face." She finished by saying, "so there's a sense in which it's so compartmentalized that it really becomes prohibitive to like, just intuitively caring for the individual as they are and meeting them where they're at." 
Third, although service providers predominantly reported that their organization's policies did not restrict treatment, a sizeable percentage $13 \%(n=8)$ of service providers reported barriers. For those respondents, CMHC policies do not allow for discretionary decision-making with criminal justice clients who are resistant, at least initially, to treatment because they are mandated as opposed to voluntarily seeking treatment. An addictions therapist provided an example of how this type of client can impact others in group settings. She stated that an individual who "makes it very clear that they have no intention, nor do they want to get any help, or even someone that is psychotic...psychiatrically is impacting the group as a whole." She further explained the challenge to keep resistant clients engaged, behave appropriately, and how some psychiatric symptoms are not helpful in a group setting, and yet oftentimes there are no alternatives. Along the same line, service providers also described how difficult it can be to make clients be more compliant with treatment (e.g., keep appointments, medication management) overall.

\section{Law as the Greatest Barrier to Treatment}

According to service providers, law was the greatest barrier to treating this population. Of the entire sample, over $90 \%(n=55)$ reported barriers related to one of the following areas: Medicaid \& the Health Insurance Portability and Accountability Act (HIPAA), conflict with the criminal justice system, and funding. Only six providers in the sample stated that law did not affect their treatment decisions.

\section{Medicaid \& HIPAA}

As aforementioned, the effects of organizational variables on treatment decisions are complex. Consistent with findings from the previous sections, Medicaid was the greatest law-related barrier for service providers $(n=36,59 \%)$. Again, legal concerns associated with Medicaid were frequently related to licensure restrictions for service providers. Eight respondents described difficulty in working with Medicaid as a payer source in that reimbursements for some services, are only covered if provided by a doctoral-level health services provider in psychology (HSPP) or a LCSW and not covered if provided by a LMHC. Respondents described the unintended difficulties for clients and providers, including higher caseloads, difficulty with staffing, their ability to meet client treatment needs, and the effect this has on organizational budget. Service providers also reported barriers related to HIPAA. For example, "HIPAA laws are my biggest headache. And I know that they protect clients and you can if it's an emergency you know, talk to people and you know parole, probation thinks that HIPAA doesn't apply to them though sometimes we think it does apply to them and the clients 
are told they have to sign a release which doesn't necessarily help the relationship". In other examples, service providers $(n=5,8 \%)$ explained how HIPAA limited them in providing the most appropriate treatment. In one circumstance, a client refused to check one of the boxes on the release of information for probation and stated, "[n]o I don't want probation to know about me and I'm like not good." The respondent explained that without the client's consent, due to HIPAA restrictions, she was unable to discuss with her client's probation officer how well he was doing related to his Schizophrenia.

\section{Conflict with the Criminal Justice System}

Respondents described conflict with the criminal justice system as another one of the greatest barriers to treatment. Most often this challenge related to conflicting opinions from criminal justice referring agencies about treatment. For example, three service providers described difficulty with law enforcement's perception of the lack of punitiveness in treatment. One service explained her experiences with local law enforcement personnel, “They, they don't understand what we do. They think that we should seclude and restrain people and they get mad at us for not doing a good job because we have people that are agitated and we're very hands off and told not to touch and so, that's our policy. That's basically DOHA's [Department of Health and Aging] policy too, I think."

Although less common, another example of the criminal justice system's influence on treatment was described by two respondents. One stated that her greatest law-related challenge, saying, "the law won't stay out of my clinical practice." Another service provider described a different frustration with the local criminal justice system:

Quite frankly the Vivitrol reps went out to all these judges and all these tiny counties in Indiana and just put the hard sell on them....and I think because they were desperate for treatment so like that's a case full of people were trying to do the right thing...now I see all these people who refuse to try Vivitrol because they were forced, basically forced, coerced, I mean they signed the plea agreement but you know, if you said 'hey you can stay here for ninety more days or you can take this shot and get out'...like I'd take the shot.

Finally, other respondents in this category described concerns regarding mandatory minimum sentencing and arrests for non-violent charges. Service providers were particularly concerned with how these laws further disproportionately harm this population. Most commonly, respondents referenced collateral consequences such as 
gaining employment and housing, state benefits for housing and food, and pursuing college education from an admissions and financial aid standpoint. They argued that criminal justice practices of punishment instead of treatment are placing an undue burden on both criminal justice and mental health systems.

\section{Funding}

Legislative funding was also one of the greatest barriers for respondents $(n=6,9.8 \%)$ and can be best described as marginalization through a lack of overall funding for mental health treatment. As an Addictions Therapist explained, "we're not funding it, we're not helping it." Service providers described the circumstances for their clients as lacking overall resources to divert them from the criminal justice system and the simple lack of treatment slots available due to lack of funding. Moreover, 17 (28.9\%) service providers described Medicaid as a driving force behind struggling budgets and restrictions on treatment options in a number of ways: Medicaid's low reimbursement rates, requirements to accept Medicaid, and the limited amount of Medicaid funding from the State. A service provider elaborated on the complex nature of budgets and Medicaid when she said, “[y]ou know? insurance runs the world, right?”

For service providers, Medicaid's low reimbursement rates and particularly the lack of increase in reimbursement for Medicaid's rehab option (MRO) have contributed to their organization's difficulty in providing care and competitive salaries. Further, according to service providers the requirements to accept Medicaid as a payer source for clients is "very demanding" considering their reimbursement rates, and therefore, places an undue burden on service providers. The reality of the funding situation according to one administrative service provider is that "it gets away then from really the evidence-based practice." Therefore, minimal resources with less funding, are spread across all clients making it difficult to provide appropriate treatment.

\section{Discussion}

A long-standing history of scholarship has examined the disproportionate criminal justice involvement for individuals with SMI. Notwithstanding the process and goals of deinstitutionalization, and despite the clear illustration that non-fragmented and appropriate treatment can ameliorate symptoms of SMI and reduce recidivism for this population, appropriate treatment to address both criminogenic behavior and mental health is inadequate for criminal justice-involved individuals in communities. This study revealed a burgeoning number of scholarly inquiries that explored decision making processes. Despite the continued increase in empirical evaluations of 
organizational effects on decisions, research has yet to examine how these variables effect treatment for criminal justice clients with SMI. This research produced a number of key findings that provide insight into the intricacies of organizational effects on treatment decisions for criminal justice-involved clients with SMI. Thus, results from this research can be used to inform not only mental health policy and practice, but also criminal justice policy and practice.

\section{RQ 1: How do CMHC service providers perceive their organization's budget to affect mental health treatment for criminal justice clients with SMI?}

The second greatest organizational barrier to treatment was budget; almost 80\% $(\mathrm{n}=48)$ of CMHC service providers reported budgetary issues related to treatment decisions. While service providers expressed some concern with their organization's ability to provide newer treatment options for this population, respondents largely expressed frustration with their organization's limited ability to hire and pay competitive salaries for qualified employees and to fund service provider trainings. The general sentiment from respondents was that there just is not enough funding available.

Considering salary-related concerns, CMHCs are forced to hire service providers with less experience and training. But this comes at a cost. Administrative service providers describe staffing issues as a double-edged sword in that they are unable to attract qualified staff given the salaries they can offer and therefore, recent graduates are the most likely to be hired and it's the CMHCs responsibility to provide the necessary training. Unfortunately, this training is difficult, expensive, and time-consuming. Many service providers described graduate-level training as insufficient to prepare service providers to treat a population with complex needs. Further, most service providers indicated that they received no or minimal graduate-level education on the treatment of criminal justice populations despite their prevalence in CMHCs. Therefore, new hires are not only undertrained but as one service provider described, they are new to the idea of treating criminal justice involved clients who are "very complicated" and may require the most intense treatment available. Beyond concerns of manpower, service providers also described issues with treatment resources in general. While concerns varied by organization, respondents explained that their organization's budget limited what services are provided. Although evidence-based practices are required in treatment, there are newer and more innovative treatment protocols available. Yet, budgets do not allow for additional treatment modalities as 
organizations already struggle with providing treatment given the need in the community and the resources that are already spread thin.

Unfortunately for service providers, the qualitative data suggested that organizations are constrained by the larger system of insurance, more specifically Medicaid, which is out of their immediate control. This finding is particularly salient as criminal justice clients with SMI are primarily insured by Medicaid, unlike non-criminal justiceinvolved clients (Cummings et al., 2013). In essence, service providers explained that Medicaid has failed to keep up with the needs of this population. The emphasis for Medicaid is to require extensive provider reporting for a population of clients that can sometimes fail to accomplish daily tasks (e.g., showering, getting in a vehicle, completing paperwork, etc.) which takes away from the available time to provide treatment, and in return, reimburse as little as possible.

\section{RQ 2: How do CMHC service providers perceive their organization's goals to} affect mental health treatment for criminal justice clients with SMI?

Most respondents (55\%) reported that their organization's goals were general for all clients. However, regardless of general or specific goals, service providers described goals as client-centered. For those with general goals, service providers explained that this flexibility allowed them to focus on individualistic treatment and, therefore, are inherently broad enough to encompass client needs specific to criminal justice involvement and SMI. Comparatively, organizations with specific goals described more measurable outcomes such as helping clients lead healthy \& productive lives without the structure of the criminal justice system, as well as helping clients developing the skills to locate and access needed resources such as health insurance, housing, and state benefits.

Although most service providers who provide treatment under general goals did not express any major concerns, those who did described how the lack of specificity might be detrimental for client's long-term success as the organization does not see the larger picture of recidivism. This is concerning as criminal justice-involved individuals with SMI historically recidivate at higher rates (Baillargeon et al., 2009; Bales et al., 2017; Daniel, 2007), compared to their non-SMI counterparts. If as studies show, criminal justice-involved individuals fail to receive appropriate treatment while incarcerated (Abramson, 1972; Barr, 2003) and in the community (Abramson, 1972; Barr, 2003; Mallik-Kane \& Visher, 2008), how will this issue be addressed and what specifically is standing in the way of accomplishing this goal? One service provider provided an explanation - financial concerns. It is well documented that CMHCs are 
underfunded and if this respondent's sentiment is correct that CMHCs are overwhelmed with keeping their doors open as opposed to the criminogenic concerns of a population that is disproportionally incarcerated and fails to receive appropriate treatment to address those concerns, then budget must be addressed.

\section{RQ 3: How do CMHC service providers perceive their organization's policies to affect mental health treatment for criminal justice clients with SMI?}

Overwhelmingly, service provider's sentiment was that CMHC policies did not impact their treatment decisions. Instead, respondents were mostly concerned with policies driven by Medicaid and the criminal justice system. Service providers expressed concerns with Medicaid restrictions regarding what treatment and who can provide those treatments. According to respondents, some treatment is difficult if not impossible to justify regardless of its necessity and impact. Relatedly, service providers explained the documentation process like a game in that they must find a way to play the system for the benefit of the client. Finally, Medicaid also restricts LMHC providers from providing reimbursable treatment to clients. Instead, despite the specificity of LMHC provider's training related to mental health, Medicaid only allows reimbursement for providers who hold a LSCW or HSPP licensure. Given the already complicated issue of staffing and salaries, this restriction seems arbitrary and only further limits the available resources despite the amount of need in communities.

\section{RQ 4: How do CMHC service providers perceive law to affect mental health treatment for criminal justice clients with SMI.}

Law was the greatest challenge for service providers and arguably drove most of this study's findings. Virtually all service providers reported law as a barrier to treatment $(n=55,90 \%)$. Service provider concerns centered around their previously mentioned budgetary challenges as it related to legislative funding and low Medicaid reimbursements. Throughout interviews, service providers described the difficulty in providing direct care under Medicaid, especially as a LMHC as opposed to a LCSW. This law-related barrier is particularly problematic as approximately $16 \%(n=10)$ and $8 \%(n=5)$ of service providers in this sample previously earned a LCSW and a LMHC, respectively. As one service provider explained, the training is basically the same for both LCSWs and LMHCs, except LMHCs have more focused training on this population of clients.

Other key findings from this portion of the qualitative analysis included service provider perceptions of sentencing for non-violent offenses, and HIPAA laws which 
protect the confidentiality of clients. Respondents described collateral consequences of felony convictions for their clients and the effect it has on clients in relation to obtaining jobs and housing, state benefits, and barriers related to higher education. Another common law-related barrier was the anti-rehabilitative nature of the criminal justice system and Indiana's corresponding mandatory minimum sentencing structure for non-violent offenses, specifically low-level drug offenses. For those who referenced confidentiality, they described both the ethical need to withhold information from criminal justice referring agencies and the competing need to share additional information that might aid in the successful treatment of clients.

As with any study, it is important to discuss its limitations. The first limitation is the nature in which the sample was obtained. As no complete list of Indiana CMHC service providers exists, the analysis relied on purposive and snowball sampling methods via email. Therefore, the generalizability of these findings is limited. Second, the researcher was limited to a criminologist without training in social work, psychiatry, or the delivery of mental health services for individuals with criminal justice involvement with SMI. This study would have benefited from collaboration with a clinician or social worker to further tease out service provider responses. Future research in this area should consider an interdisciplinary, collaborative approach. These limitations underscore the importance of future research dedicated to understanding such decisions and their long-term effects of treatment decisions on individuals who are criminal justice involved with SMI.

\section{Implications}

While the findings from the current study should not be considered generalizable to all Indiana service providers or to $\mathrm{CMHC}$ organizations in other states, initial findings can provide context for future research. Given the salience of Medicaid as a driving factor in many of this study's findings, policymakers and legislators should consider the role of Medicaid funding on organizational budgets. Additionally, in light of these findings and because prior research suggests that a sizeable percentage of CMHCs in the United States do not accept Medicaid (Cummings et al., 2013), future qualitative research should examine how community service provider treatment decisions vary across organizations. Relatedly, future quantitative empirical research will be especially important in determining how CMHC service provider perceptions compare to service providers in private practices, prisons, and civil and criminal justice organizations, as well as to examine the longitudinal effects of these treatment decisions on recidivism in this population. Finally, service providers also tend to report 
dissatisfaction with the current mandatory minimum sentencing guidelines for nonviolent drug offenses. The modal percentage of comorbid substance use for clients on service provider caseloads was $100 \%(n=61)$. Given that treatment slots are limited, and budgets are restricted by limited Medicaid and legislative funding, legislators should consider an evaluation of how burdened incarcerated settings are with nonviolent drug offenses and the amount of resources necessary in jails, prisons, and CMHCs to incarcerate and treat this population. Nationally, other states have legalized the use of recreational marijuana. Indiana legislators should consider following the path set forward by other states.

While it was not within the scope of this study to explore the role of caseload size on community mental health treatment decisions for criminal justice clients with SMI, over $13 \%$ of service providers volunteered that their caseload was higher than it should be given their administrative responsibilities. Given this finding, and the corresponding empirical support of caseload size on decision making (Arazan et al., 2019; Ulmer \& Bradley, 2006), future research on the role of organizational-level challenges to treatment should extend and refine the current analysis to include the effect of caseload size on service provider perceptions. Related qualitative research would do well to consider why CMHCs do not have criminal justice-specific goals. Finally, considering unsolicited findings from service providers regarding the effects of co-occurring SUDs and trauma histories, future research qualitative and quantitative research should explore these relationships.

\section{References}

Aarons, G. A., Wells, R. S., Zagursky, K., Fettes, D. L., \& Palinkas, L. A. (2009).

Implementing evidence-based practice in community mental health agencies: A Multiple stakeholder analysis. American Journal of Public Health, 99(11), 2087-2095. https://doi.org/10.2105/AJPH.2009.161711

Abramson, M. F. (1972). The criminalization of mentally disordered behavior: Possible side-effect of a new mental health law. Psychiatric Services, 23(4), 101-105.

Adams, N., \& Grieder, D. M. (2013). Treatment planning for person-centered care: Shared decision making for whole health. Academic Press.

Arazan, C. L., Bales, W. D., \& Blomberg, T. G. (2019). Courtroom context and sentencing. American Journal of Criminal Justice, 44(1), 23-44. https://doi.org/10.1007/s12103-018-9444-8 
Baillargeon, J., Binswanger, I. A., Penn, J. V., Williams, B. A., \& Murray, O. J. (2009). Psychiatric disorders and repeat incarcerations: The Revolving prison door. American Journal of Psychiatry, 166(1), 103-109. https://doi.org/10.1176/appi.ajp.2008.08030416

Baillargeon, J., Hoge, S. K., \& Penn, J. V. (2010). Addressing the challenge of community reentry among released inmates with serious mental illness. American Journal of Community Psychology, 46(3), 361-375. https://doi.org/10.1007/s10464-0109345-6

Bales, W. D., Nadel, M., Reed, C., \& Blomberg, T. G. (2017). Recidivism and inmate mental illness. International Journal of Criminology and Sociology, 6(0), 40-51. https://doi.org/10.6000/1929-4409.2017.06.05

Barr, H. (2003). Transinstitutionalization in the courts: Brad H. v. City of New York, and the fight for discharge planning for people with psychiatric disabilities leaving Rikers Island. Crime \& Delinquency, 49(1), 97-123.

https://doi.org/10.1177/0011128702239238

Beidas, R. S., Aarons, G., Barg, F., Evans, A., Hadley, T., Hoagwood, K., Marcus, S., Schoenwald, S., Walsh, L., \& Mandell, D. S. (2013). Policy to implementation: Evidencebased practice in community mental health - study protocol. Implementation Science, 8(1), 38. https://doi.org/10.1186/1748-5908-8-38

Berk, M. L., \& Schur, C. L. (1998). Access to care: How much difference does medicaid make? Health Affairs, 17(3), 169-180. https://doi.org/10.1377/hlthaff.17.3.169

Bonfine, N., Wilson, A. B., \& Munetz, M. R. (2019). Meeting the needs of justiceinvolved people with serious mental illness within community behavioral health systems. Psychiatric Services, 71(4), 355-363.

https://doi.org/10.1176/appi.ps.201900453

Bowen, S., \& Zwi, A. B. (2005). Pathways to "Evidence-Informed" Policy and Practice: A Framework for Action. PLoS Medicine, 2(7), e166.

https://doi.org/10.1371/journal.pmed.0020166

Brown, S. A., \& Lewis, K. (2015). Hope for successful implementation of psychosocial/psychiatric rehabilitation in the forensic mental health setting. Psychiatric Rehabilitation Journal, 38(4), 365-370. https://doi.org/10.1037/prj0000086 Cascio, M. A., Lee, E., Vaudrin, N., \& Freedman, D. A. (2019). A team-based approach to open coding: Considerations for creating intercoder consensus. Field Methods, 
31(2), 116-130. https://doi.org/10.1177/1525822X19838237

Castro, E. M., Van Regenmortel, T., Vanhaecht, K., Sermeus, W., \& Van Hecke, A. (2016). Patient empowerment, patient participation and patient-centeredness in hospital care: A concept analysis based on a literature review. Patient Education and Counseling, 99(12), 1923-1939. https://doi.org/10.1016/j.pec.2016.07.026

Cummings, J. R., Wen, H., Ko, M., \& Druss, B. G. (2013). Geography and the Medicaid mental health care infrastructure: Implications for health care reform. JAMA Psychiatry, 70(10), 1084-1090. https://doi.org/10.1001/jamapsychiatry.2013.377

Cunningham, P. J., \& O’Malley, A. S. (2008). Do reimbursement delays discourage medicaid participation by physicians? Health Affairs, 27(Supplement 1), w17-w28. https://doi.org/10.1377/hlthaff.28.1.w17

Daniel, A. (2007). Care of the mentally ill in prisons: Challenges and solutions. The Journal of American Academy of Psychiatry and the Law, 406-410. http://jaapl.org/content/35/4/406.long Elpers, J. R. (1989). Public Mental Health Funding in California, 1959 to 1989. Psychiatric Services, 40(8), 799-804. https://doi.org/10.1176/ps.40.8.799

Frank, R. G., \& Glied, S. A. (2006). Better but not well: Mental health policy in the United States since 1950. John Hopkins Press.Gayman, M. D., Powell, N. K., \&

Bradley, M. S. (2018). Probation/parole officer psychological well-being: The Impact of supervising persons with mental health needs. American Journal of Criminal Justice, 43(3), 509-529. https://doi.org/10.1007/s12103-017-9422-6

Glaze, L. E., \& Kaeble, D. (2013). Correctional populations in the United States, 2013 (pp. 1-13). Department of Justice, Office of Justice Programs, Bureau of Justice Statistics. https://www.bjs.gov/content/pub/pdf/cpus13.pdf

Goldberg, D. M., \& Lin, H.-C. (2017). Effects of the mental health parity and addictions equality act on depression treatment choice in primary care facilities. The International Journal of Psychiatry in Medicine, 52(1), 34-47. https://doi.org/10.1177/0091217417703289

Guindo, L. A., Wagner, M., Baltussen, R., Rindress, D., van Til, J., Kind, P., \& Goetghebeur, M. M. (2012). From efficacy to equity: Literature review of decision 
criteria for resource allocation and healthcare decisionmaking. Cost Effectiveness and Resource Allocation, 10(1), 9. https://doi.org/10.1186/1478-7547-10-9

Janati, A., Hasanpoor, E., Hajebrahimi, S., Sadeghi-Bazargani, H., \& Khezri, A. (2018). An evidence-based framework for evidence-based management in healthcare organizations: A Delphi study. Ethiopian Journal of Health Sciences, 28(3), 305-314. https://doi.org/10.4314/ejhs.v28i3.8Jecker, N. S., Jonsen, A. R., \& Pearlman, R. A. (2011). Bioethics. Jones \& Bartlett Publishers.

Kennedy-Hendricks, A., Huskamp, H. A., Rutkow, L., \& Barry, C. L. (2016). Improving access to care and reducing involvement In the criminal justice system for people with mental illness. Health Affairs, 35(6), 1076-1083.

https://doi.org/10.1377/hlthaff.2016.0006

Keogh, F., Pierse, T., O’Shea, E., Fitzgerald, C., \& Challis, D. (2020). Resource allocation decision-making in dementia care with and without budget constraints: A qualitative analysis. HRB Open Research, 3, 69.

https://doi.org/10.12688/hrbopenres.13147.2

Korasz, K., Miller, M., Steadman, P., Mangundu, M., \& Omosola-Ladenegan, J. (2018). Measuring complexity and quantity of community caseloads. Mental Health Practice. https://journals.rcni.com/mental-health-practice/evidence-and-practice/measuringcomplexity-and-quantity-of-community-caseloads-mhp.2018.e1278/print/abs

Lamb, H. R., \& Weinberger, L. E. (1998). Persons with severe mental illness in jails and prisons: A Review. Psychiatric Services., 49(4), 483-492. https://doi.org/10.1176/appi.ps.201500076Légaré, F., \&

Witteman, H. O. (2013). Shared Decision Making: Examining Key Elements And Barriers To Adoption Into Routine Clinical Practice. Health Affairs, 32(2), 276-284. https://doi.org/10.1377/hlthaff.2012.1078

Lipsky, M. (1980). Street-Level Bureaucracy; Dilemmas of the Individual in Public Services. Russell Sage Foundation.

Lurigio, A. J. (2011). People with serious mental illness in the criminal justice system: Causes, consequences, and correctives. The Prison Journal, 91(3), 66S-86S. https://doi.org/10.1177/0032885511415226

Mallik-Kane, K., \& Visher, C. A. (2008). Health and prisoner reentry: How physical, mental, and substance abuse conditions shape the process of reintegration (No. 
719772011-001) [Data set]. American Psychological Association. https://doi.org/10.1037/e719772011-001

Morata, L. (2018). An evolutionary concept analysis of futility in health care. Journal of Advanced Nursing, 74(6), 1289-1300. https://doi.org/10.1111/jan.13526

Pierse, T., Keogh, F., Challis, D., \& O’Shea, E. (2021). Resource allocation in dementia care: Comparing the views of people with dementia, carers and health and social care professionals under constrained and unconstrained budget scenarios. Aging \& Mental Health, O(0), 1-9. https://doi.org/10.1080/13607863.2021.1889969

Prins, S. J., Draper, L., Center, J., \& John, D. (2009). Improving outcomes for people with mental illnesses under community corrections supervision: A Guide to researchinformed policy and practice. Council of State Governments Justice Center. https://csgjusticecenter.org/wp-content/uploads/2020/02/Community-CorrectionsResearch-Guide.pdf

Saldana, J. (2015). The coding manual for qualitative researchers. SAGE Publications.

Siegler, M. (1985). Who should decide?: Paternalism in health care, by James F. Childress. Perspectives in Biology and Medicine, 28(3), 452-456.

https://doi.org/10.1353/pbm.1985.0033Stewart, C. (2011). Futility Determination as a Process: Problems with Medical Sovereignty, Legal Issues and the Strengths and Weakness of the Procedural Approach. Journal of Bioethical Inquiry, 8(2), 155-163. https://doi.org/10.1007/s11673-011-9297-z

Trompenaars, F. (1994). Riding the waves of culture: Understanding cultural diversity in business. Breadly.

Ulmer, J. T., \& Bradley, M. S. (2006). Variation in trial penalties among serious violent offenses. Criminology, 44(3), 631-670. https://doi.org/10.1111/j.17459125.2006.00059.x

Weick, K. E. (1976). Educational organizations as loosely coupled systems. Administrative Science Quarterly, 21(1), 1-19. https://doi.org/10.2307/2391875

Whiteford, L. M. (2019). New approaches to human reproduction: Social And ethical dimensions. Routledge.

Yank, G. R., Hargrove, D. S., \& Davis, K. E. (1992). Toward the financial integration of public mental health services. Community Mental Health Journal, 28(2), 97-109. 
https://doi.org/10.1007/BF00754277

\section{Contributor's Bio}

Dr. Brittany Hood is an assistant professor of social sciences at Texas A\&M International University. Her primary area of interest explores the intersection of mental health and offending with particular emphasis on the experiences of individuals with mental illness across police, courts, and corrections. Her research uses both quantitative and qualitative methods to better understand what works in reducing recidivism for this population, stigma against mental illness and mental health treatment, as well as how criminal justice and mental health agency decision making influences the treatment of this population.

\section{Acknowledgement}

The author thanks Drs. Michell Salyers and Matthew Aalsma who initially provided qualitative training and the help in pursuit of this career path. Dr. Bradley Ray must also receive acknowledgment in his role as an early mentor. Most importantly, Drs. Bruce Sales, Marla Sandys, and Richard Lippke (Indiana University) should be recognized for their guidance and support throughout the dissertation development and writing process. Acknowledgment must also be given to colleagues and the reviewers who provided further guidance in the development of this manuscript. 